\title{
Correction to: Consilience, Truth and the Mind of God
}

\section{Correction to: \\ R. J. Di Rocco, Consilience, Truth and the Mind of God, https://doi.org/10.1007/978-3-030-01869-6}

The book was inadvertently published with an incorrect ToC where Chapter 8 subchapter was not indented (Consilience, Truth and the Mind of God: A Synthesis). It is now corrected as

Recollection and Synthesis

About the Universe-Multiverse

About Logic

About the Ontological Question

The Modified Argument from Truth

In Chapter 3, Page 35 in footnote, the $\mathrm{K}_{\mathrm{B}}$ units symbol was wrongly published. This is now corrected as $\mathrm{K}_{\mathrm{B}}$ has units of $\mathrm{J} / \mathrm{K}$ so the right side of $\mathrm{Eq} 3.9$, which is (T) $\left[\mathrm{K}_{\mathrm{B}} \Sigma \mathrm{p}_{\mathrm{i}} \log _{\mathrm{b}}\left(\mathrm{p}_{\mathrm{i}}\right)\right]$, has units of $\mathrm{oK}\left(\mathrm{J} /{ }^{\circ} \mathrm{K}\right)=\mathrm{J}$.

Also, in Page 137 Chapter 8, missed to italicize the sub-quote.

The sub-quote encompasses "it is clear to every reasonable mind...which a greater cannot be thought. (Anselm's Reply to Guanilo 8)". This is now corrected.

The updated version of these chapters can be found at https://doi.org/10.1007/978-3-030-01869-6_3

https://doi.org/10.1007/978-3-030-01869-6_8

https://doi.org/10.1007/978-3-030-01869-6 